\title{
Clinical Effectiveness of Complex Decongestive Physiotherapy for Malignant Lymphedema: A Pilot Study
}

\author{
Ki Hun Hwang, MD, Ho Joong Jeong, MD, Ghi Chan Kim, MD, Young-Joo Sim, MD \\ Department of Physical Medicine and Rehabilitation, Kosin University College of Medicine, Busan, Korea
}

Objective To evaluate the effect of complex decongestive physiotherapy (CDPT) on malignant lymphedema patients.

Methods Patients ( $\mathrm{n}=22$ ) with malignant lymphedema of the upper or the lower limb were assigned to this study. CDPT without manual lymphatic drainage (MLD) was used five times per week for two weeks. The main outcome measurements included measurement of the circumference of the limb (proximal, distal, and total) to assess volume changes. We also employed the visual analog scale (VAS) to evaluate pain, and the short form-36 version 2 questionnaire (SF-36) to assess quality of life (QOL). All items were assessed pre and post-treatment for each patient.

Results There was a statistically significant difference in the volume change of the upper limbs $(3.7 \%, \mathrm{p}=0.001)$ and the lower limbs (10.9\%, $\mathrm{p}=0.001)$. A 1.5 point reduction on the ten-point VAS was noted after CDPT. The scores on the physical and the mental components of the SF- 36 showed statistical improvement after treatment $(\mathrm{p}=0.006$, $\mathrm{p}=0.001$, respectively).

Conclusion These results suggest that all components of the CDPT program except MLD are helpful in treating malignant lymphedema in terms of pain reduction and reduction of the volume of the affected upper or lower limb. This treatment regimen also has positive effects on QOL.

Keywords Cancer, Lymphedema, Physiotherapy, Quality of life, Pain

Received March 14, 2012; Accepted September 17, 2012

Corresponding author: Young-Joo Sim

Department of Physical Medicine and Rehabilitation, Kosin University College of Medicine, 262 Gamcheon-ro, Seo-gu, Busan 602-702, Korea Tel: +82-51-990-6261, Fax: +82-51-241-2019, E-mail: oggum@hanmail. net

(c) This is an open-access article distributed under the terms of the Creative Commons Attribution Non-Commercial License (http://creativecommons. org/licenses/by-nc/3.0) which permits unrestricted noncommercial use, distribution, and reproduction in any medium, provided the original work is properly cited.

Copyright $\odot 2013$ by Korean Academy of Rehabilitation Medicine

\section{INTRODUCTION}

Lymphedema is an abnormal accumulation of stagnant protein-rich fluid in the interstitial matrices of the limbs. The high concentration of protein causes the colloid osmotic pressure to increase, which accelerates fluid transfer into the interstitial space [1]. Lymphedema may be present in the extremities, trunk, abdomen, head and neck, external genitalia, and inner organs. Patients with lymphedema may experience pain, swelling, tightness and heaviness in the affected area, and the documented side effects include cosmetic and functional problems, 
cellulitis, and other infections, as well as lymphangiosarcoma $[2,3]$.

Most patients develop benign lymphedema after surgery and/or radiation therapy for various cancers including breast, uterus, prostate, bladder, lymphoma, melanoma, and other cancers [4]. However, malignant lymphedema can develop when there is impaired lymph flow in the lymphatic channels and/or lymph nodes due to malignant tumor spread [5]. Sometimes, malignant lymphedema can be the first sign of tumor recurrence or an unknown tumor growth. Lymphedema that develops after breast cancer therapy is the first symptom of tumor recurrence in about $10 \%$ of patients [6]. About $1 \%$ to $2 \%$ of the cases of malignant lymphedema are generally secondary to previously unidentified tumors [6]. Approximately $50 \%$ of patients with recurrent gynecological cancer develop malignant lymphedema. However, most examples of malignant lymphedema described in the literature are case reports [5], which do not always include information about the demographics, the disease, or the treatment.

Unlike benign lymphedema, the malignant form can have an acute onset, show rapid progression, result in changes in skin color and be accompanied by general weakness [5]. Therefore, early treatment is indicated because malignant lymphedema tends to progress and causes discomfort and psychological stress for patients [5]. There is a paucity of studies that report the effectiveness of physiotherapy for malignant lymphedema. The reported studies focused on the treatment of many patients with malignant lymphedema only in relation to the medical management of pain. Our study was designed to investigate the effects of complex decongestive physiotherapy (CDPT) in patients with malignant lymphedema with regard to volume reduction of upper and lower limb swelling, as well as the effect of treatment on patient quality of life (QOL).

\section{MATERIALS AND METHODS}

\section{Subjects}

The patients were consecutively selected by one physician from the inpatient clinic in the Department of Rehabilitation Medicine at Kosin University Hospital, Korea, from January 2010 to December 2010. Cancer survivors, who were diagnosed with malignant lymphedema by a physician, were included. The criteria used for the diag- nosis of malignant lymphedema in cancer survivors were 1) a greater than $2 \mathrm{~cm}$ circumference difference between the affected upper or lower limb and the normal upper or lower limb; 2) a diagnosis of lymphedema via lymphoscintigraphy (decreased uptake or no uptake by the lymph nodes, dermal backflow, poor to no visualization of the collateral and main lymphatics, and decreased or no clearance of radioisotope from the injection site) [7]; 3) lymphatic channel or lymph node invasion in the axilla, the pelvis, or the lumbar or inguinal areas diagnosed via imaging study; and 4) limb swelling that appeared to be aggressively and rapidly progressing. Exclusion criteria included 1) age older than 80 years, 2) bilateral lymphedema of the upper or lower limbs, 3) patients with benign lymphedema before malignant metastasis, 4) patients with induced lymphedema during radiotherapy or chemotherapy, 5) vascular disorders that might cause lymphedema, and 6) poor communication skills or low treatment compliance.

We recruited 33 patients, who had never received treatment for their lymphedema. The patients provided informed consent, and the study protocol conformed to the ethical guidelines of the Declaration of Helsinki. The patients completed a survey in which the purpose of the study was explained to them. Those who agreed to participate were included. Eleven patients were excluded during this process, leaving a total of 22 patients who were selected to proceed with the study.

\section{Treatment method and process}

All of the 22 patients received the following components of CDPT: non-elastic bandage compression therapy, remedial exercise, and skin care. Only the manual lymphatic drainage (MLD) was not utilized. Therapy was provided five times a week for two weeks by one physical therapist. Drugs for anticancer treatment and pain were allowed, but were not changed during the two weeks of the study.

\section{Measurement method}

We measured the volume of the upper or the lower limbs at $3 \mathrm{~cm}$ intervals along the axis of ordinates of each extremity. This axis was based on the anatomic reference line that connects the bilateral epicondyles or condyles of the elbow and knee. The proximal part of the upper and lower limbs was measured from the anatomic reference line to levels of the axilla and pubic symphysis. And distal 
portion was measured from the anatomic reference line to as the hands and feet area distal $6 \mathrm{~cm}$ the medial and lateral styloid process of the wrist and malleolus of the ankle. The circumference measurements obtained in this manner were then used to calculate the volume of each segment, which was treated as a truncated cone using the following formula: $\mathrm{V}=\mathrm{h}\left(\mathrm{Cl}^{2}+\mathrm{C} 1 \mathrm{C} 2+\mathrm{C}^{2}\right) / 12 \pi[8]$. The sum of the volumes of the proximal and distal portions of the upper or lower limbs was taken as the total volume. The volume measurements were done twice-before and after the two weeks of CPDT.

Patient QOL was also assessed at the measurement visit. The Korean version of the Medical Outcomes 36-item Short Form Health Survey (SF-36) 0-100 score was used. The SF-36 includes eight multi-item scales that contain two to ten items each, plus a single item to assess the state of health. The multi-item scales cover the dimensions of physical functioning, physical role functioning, bodily pain, general health perceptions, mental health, emotional role functioning, social role functioning, and vitality [9]. The multi-item scales are separated into the physical component summary (PCS), which includes physical functioning, physical role functioning, bodily pain and general health perceptions, and the mental component summary (MCS), which includes mental health, emotional role functioning, social role functioning, and vitality. These summaries were used to confirm changes that occurred as a result of treatment.

We used the ten-point visual analog scale (VAS) to evaluate pain intensity. Patients were asked to indicate the intensity of pain in the limbs with lymphedema. The pain intensity was measured before and after two weeks of CDPT.

\section{Statistical analysis}

SPSS ver. 14.0 (SPSS Inc., Chicago, IL, USA) was used for all analyses. A paired t-test was employed to assess the significance of differences in volume of the upper and

Table 1. Subject characteristics

\begin{tabular}{cclclllc}
\hline & $\begin{array}{c}\text { Age } \\
\text { (yr) }\end{array}$ & Sex & $\begin{array}{c}\text { Site of } \\
\text { swelling }\end{array}$ & Cancer & \multicolumn{1}{c}{ Site of metastasis } & RT & CT \\
\hline 1 & 53 & Female & R (L) & Cervix & Lung, pelvic node & No & Yes \\
\hline 2 & 80 & Female & L (L) & Cervix & Rectum, lung & No & Yes \\
\hline 3 & 56 & Female & R (L) & Cervix & Mesentery, bladder & No & Yes \\
\hline 4 & 58 & Male & R (L) & Stomach & Peritoneum, pelvic node & No & Yes \\
\hline 5 & 71 & Male & L (L) & Esophagus & Thoracic spine, abdomen, pelvic node & No & Yes \\
\hline 6 & 62 & Female & R (L) & Stomach & Liver, peritoneum & No & Yes \\
\hline 7 & 51 & Male & L (L) & Rectum & Para-aortic, left iliac node & No & Yes \\
\hline 8 & 57 & Female & R(L) & Cervix & Pelvic node & Yes & Yes \\
\hline 9 & 69 & Female & R(L) & Cervix & Lung, rectum, bladder & No & Yes \\
\hline 10 & 63 & Female & R(L) & Uterus & Lung, bladder & No & Yes \\
\hline 11 & 69 & Female & R(L) & Cervix & Spine, rib, sternum & Yes \\
\hline 12 & 66 & Male & L (L) & Stomach & Peritoneum & No & Yes \\
\hline 13 & 72 & Female & R (L) & Colon & Lung, pelvic node & No & Yes \\
\hline 14 & 54 & Female & R (L) & Cervix & Lung, pelvic node & No & Yes \\
\hline 15 & 60 & Male & R (L) & Rectum & Pelvic node & Yes & Yes \\
\hline 16 & 35 & Female & L (U) & Breast & Axillary node & Yes & Yes \\
\hline 17 & 57 & Female & L (U) & Breast & Axillary and subclavian node & Yes & Yes \\
\hline 18 & 52 & Female & L (U) & Breast & Contralateral breast & No & Yes \\
\hline 19 & 62 & Female & R (U) & Breast & Both lung & Yes & Yes \\
\hline 20 & 79 & Female & L (U) & Breast & Lung & Yes & Yes \\
\hline 21 & 35 & Female & L (U) & Breast & Axillary node & Yes & Yes \\
\hline 22 & 58 & Female & R (U) & Breast & Axillary node & Yes \\
\hline
\end{tabular}

$\mathrm{RT}$, radiotherapy; CT, chemotherapy. 
lower limbs (total, proximal and distal volume), intensity of pain and QOL before and after CDPT. And Student ttest was applied to confirm differences of volume change in the proximal and distal parts of the upper and lower limbs, respectively. In parts of PCS and MCS, we used the paired t-test before and after CDPT. In order to confirm change of PCS and MCS depending on the upper or lower limbs, Student t-test was used to compare change in parts of PCS and MCS before and after CDPT. A p-value less than 0.05 was considered statistically significant.

\section{RESULTS}

\section{Characteristics}

Twenty-two patients were enrolled in this study, and their average age was 60.0 years. There were 7 (31.8\%) and 15 (68.2\%) patients with malignant lymphedema of the upper and lower limbs, respectively. There were nine patients, who had received radiation therapy. No patient developed an infection related to malignant lymphedema (Table 1).

\section{Volume}

The total volume of the upper or the lower limb decreased by $3.7 \%$ and $10.9 \%$, respectively after two weeks of CDPT ( $\mathrm{p}=0.001$, respectively) (Tables 2,3 ). Among 22 patients, 19 patients improved in volume, but the volume of the others were increased. The reduction in the proximal area volume was greater than that of the distal area volume in both the upper limbs $(\mathrm{p}=0.015)$ and the lower limbs $(\mathrm{p}=0.016)$.

\section{Quality of life}

Using the VAS, the patients reported an average decrease of 1.6 points compared with pretreatment VAS points. However, one patient reported no change in pain

Table 2. Changes in the volume of the upper limbs

\begin{tabular}{|c|c|c|c|}
\hline \multirow{2}{*}{ Volume } & \multicolumn{2}{|c|}{ Value $\left(\mathrm{cm}^{3}\right)$} & \multirow{2}{*}{ p-value } \\
\hline & nent & Post-t & \\
\hline & $1,356.83 \pm 202.64$ & $1,339.80$ & 0.690 \\
\hline Provim & $1,888.28 \pm 299.92^{a)}$ & $1,783.91 \pm 320.27^{\mathrm{a})}$ & $0.038^{a)}$ \\
\hline otal & $3,245.11 \pm 488.83^{a)}$ & $3,123.71 \pm 465.21^{a)}$ & $0.001^{\text {a) }}$ \\
\hline
\end{tabular}

Values are means \pm standard deviations.

${ }^{a)} \mathrm{p}<0.05$, by a paired $\mathrm{t}$-test comparing before and after treatment in each group. intensity, while another patient reported an increase in pain.

In the QOL evaluation, five items such as physical functioning $(\mathrm{p}=0.001)$, physical role functioning $(\mathrm{p}=0.001)$, bodily pain ( $\mathrm{p}=0.001)$, social role functioning $(\mathrm{p}=0.008)$, and emotional role functioning $(\mathrm{p}<0.001)$ showed a statistically significant improvement. An improvement was also noted when the PCS and MCS components were analyzed separately $(\mathrm{p}=0.006, \mathrm{p}=0.001$, respectively) (Table 4). The PCS value decreased in seven patients, and four patients reported on the MCS that their quality of life had decreased. Patients with malignant lymphedema of the upper limb showed more improvement on the MCS than patients with malignant lymphedema of the lower limb $(\mathrm{p}=0.04)$. However, there was a greater improvement on the PCS in patients with malignant lymphedema of the lower limb than in patients with upper limb involvement $(p=0.03)$.

\section{DISCUSSION}

A malignant tumor spreads to other organs if no effective treatment is given or if enough time passes without the patient showing a response to the treatment. If the organ to which the malignant tumor spreads is a vital area for lymphatic drainage, eventually there can be a serious negative effect on the drainage of lymph. This problem gets worse over time, resulting in lymphedema. The severity of the lymphedema depends on the location, the extent of lymphatic transport impairment, and the availability of compensation options [5]. The most important areas that can become blocked by metastases are the lymph nodes of the inguinal, pelvic, lumbar or axillary sites. These obstructions occur not only in malignant melanoma, and rectal, prostate, penis cancers, and malignant testicular tumors, but also in vaginal, ovarian,

Table 3. Changes in the volume of the lower limbs

\begin{tabular}{llll}
\hline \multirow{2}{*}{ Volume } & \multicolumn{2}{c}{ Value $\left(\mathrm{cm}^{3}\right)$} & \\
\cline { 2 - 4 } & \multicolumn{1}{c}{ Pre-treatment } & \multicolumn{1}{c}{ Post-treatment } & p-value \\
\hline Distal & $2,968.31 \pm 555.24$ & $2,651.85 \pm 425.24$ & 0.001 \\
Proximal & $5,309.18 \pm 1,426.19$ & $4,723.11 \pm 1,240.80$ & 0.001 \\
Total & $8,277.48 \pm 1,819.93$ & $7,374.95 \pm 1,513.70$ & 0.001 \\
\hline
\end{tabular}

Values are means \pm standard deviations.

$\mathrm{p}<0.05$, by a paired t-test comparing before and after treatment in each group. 
Table 4. Comparison of clinical parameters pre- and post-treatment

\begin{tabular}{|c|c|c|c|}
\hline \multirow{2}{*}{ Parameter } & \multicolumn{2}{|c|}{ Value } & \multirow{2}{*}{ p-value } \\
\hline & Pre-treatment & Post-treatment & \\
\hline Visual analog scale & $4.82 \pm 1.37^{\mathrm{a})}$ & $3.36 \pm 1.18^{\mathrm{a})}$ & $<0.001^{\text {a) }}$ \\
\hline Physical functioning & $33.86 \pm 16.10^{\mathrm{a})}$ & $42.5 \pm 17.17^{\mathrm{a})}$ & $<0.001^{\text {a) }}$ \\
\hline Physical role functioning & $57.95 \pm 15.45^{\mathrm{a})}$ & $68.47 \pm 9.35^{\mathrm{a})}$ & $0.001^{\mathrm{a})}$ \\
\hline Bodily pain & $45.45 \pm 21.10^{\mathrm{a})}$ & $57.27 \pm 22.29^{a)}$ & $0.001^{\mathrm{a})}$ \\
\hline General health perceptions & $49.77 \pm 11.70$ & $58.18 \pm 10.53$ & 0.079 \\
\hline Physical component summary & $40.40 \pm 4.16^{\text {a) }}$ & $42.94 \pm 4.48^{\text {a) }}$ & $0.006^{\mathrm{a})}$ \\
\hline Vitality & $48.58 \pm 13.49$ & $54.26 \pm 13.96$ & 0.064 \\
\hline Social role functioning & $46.59 \pm 24.15^{\mathrm{a})}$ & $59.09 \pm 21.54^{\mathrm{a})}$ & $0.008^{\mathrm{a})}$ \\
\hline Emotional role health & $28.03 \pm 15.33^{\text {a) }}$ & $54.17 \pm 19.37^{\mathrm{a})}$ & $<0.001^{\text {a) }}$ \\
\hline Mental health & $48.64 \pm 18.20$ & $54.55 \pm 14.30$ & 0.080 \\
\hline Mental component summary & $36.38 \pm 5.30^{\mathrm{a})}$ & $42.21 \pm 5.26^{\mathrm{a})}$ & $0.001^{\mathrm{a})}$ \\
\hline
\end{tabular}

Values are means \pm standard deviation.

${ }^{a)} \mathrm{p}<0.05$, by a paired t-test comparing between before and after treatment in each group.

uterine, and breast cancers. Primary lymph node tumors as seen in Hodgkin's disease and non-Hodgkin's lymphoma can also block lymphatic drainage [5]. The primarily unilateral malignant lymphedema of the extremities has an acute onset and progresses from the central to the peripheral. Within weeks, the swelling expands rapidly and is associated with increased tension and pain because the affected tissues cannot adjust to the quickly accumulating pressure [5].

Most persons with metastatic cancer encounter different challenges than those with local or regional cancer, since they are living with a terminal disease. There are inevitable declines in QOL, increase in psychological barriers, and debilitating fatigue [10]. The increased prevalence of metastatic cancer, increased longevity after diagnosis, and the compromised QOL of patients with advanced cancer have been on the rise. This situation is prompting the need for research on interventions for malignant lymphedema from both psychological and physical perspectives. Spiegel et al. [11,12] and Spiegel [13] reported that if mental and social therapy including supportive therapy, are provided to patients with metastatic cancer, the quality of their life improves and their survival time increases. Thus, they insisted that patients should receive active treatment whether the patient has metastatic cancer or not. However, there are few studies on the treatment of malignant lymphedema of the upper or the lower limbs related to metastatic cancer.

There was a reduction in the limb volume in patients with malignant lymphedema after two weeks of CDPT without MLD. However, the proximal area volume showed a greater decrease compared with the distal area volume. The intensity of the pain also decreased after CDPT. These results show that intensive physiotherapy including non-elastic bandage compression therapy, remedial exercise, and skin care has a positive impact on patients with malignant lymphedema. CDPT without MLD can reduce limb swelling in patients with malignant lymphedema. This treatment is more effective in reducing the swelling in the proximal part than it is in reducing the volume of the distal part.

The SF-36 showed that the quality of life improved after CDPT. The evaluation was divided into a total of eight items. Of these, five items showed improvement. Both the PCS and MCS items showed statistically significant improvement. Those patients with malignant lymphedema of the upper limb reported a greater improvement on the MCS than those patients with lower limb involvement. However, the improvement on PCS in patients with malignant lymphedema of the lower limb was greater than in patients with malignant lymphedema of the upper limb. Those patients with involvement of the lower limb reported a large negative impact of the lymphedema on the performance of their daily activities including standing and walking, and this greatly limited their ability to perform physical functions. We hypothesize that active treatment for patients with malignant lymphedema of the lower limb is needed to reduce swelling and pain. This 
reduction in the volume of the malignant lymphedema can lead to improvement in the PCS. However, we are not certain of these results because of the small number of patients $(\mathrm{n}=22)$ in this study.

Many studies have reported on the use of MLD to treat malignant lymphedema with subsequent cancer spread. Herpertz [14] reported that providing MLD to patients with cancer causes cancer metastasis. Piller and Carati [15] reported similar findings. However, Preisler et al. [16] and Godette et al. [17] recommended MLD, stating it is not related to an increase in cancer metastasis. Pinell et al. [18] reported this critical intervention should not be withheld, because of the benefits of manipulative therapy. However, there is still no consensus on the relationship between treatment with MLD and cancer metastasis. In our study, MLD was excluded from the CDPT regimen because of the possibility of cancer metastasis. Therefore, we believe that CDPT without MLD can be used for patients with malignant lymphedema not only to reduce the pain and swelling, but also to improve QOL.

There are limitations of this study. First, this study had no control group. The small sample size $(n=22)$ is a second limitation. Therefore, it is difficult to generalize these results. Above all, the safety of CDPT for malignant lymphedema still remains controversial. Research investigating the relationship between MLD and cancer metastasis is still lacking. Therefore, application of CDPT for malignant lymphedema must be determined by experts, and more research studies will be needed for improving malignant lymphedema.

In conclusion, we demonstrated that treating patients with malignant lymphedema using CDPT without MLD decreased not only the patient's edema and pain, but also improved QOL. Therefore, we urge clinicians to provide more active treatment to these patients. Future studies should be aimed at a larger number of patients.

\section{CONFLICT OF INTEREST}

No potential conflict of interest relevant to this article was reported.

\section{ACKNOWLEDGMENTS}

This study was supported by a grant from Kosin University College of Medicine (2012).

\section{REFERENCES}

1. Warren AG, Brorson H, Borud LJ, Slavin SA. Lymphedema: a comprehensive review. Ann Plast Surg 2007;59:464-72.

2. Querci della Rovere G, Ahmad I, Singh P, Ashley S, Daniels IR, Mortimer P. An audit of the incidence of arm lymphoedema after prophylactic level I/II axillary dissection without division of the pectoralis minor muscle. Ann R Coll Surg Engl 2003;85:158-61.

3. Hinrichs CS, Watroba NL, Rezaishiraz H, Giese W, Hurd T, Fassl KA, et al. Lymphedema secondary to postmastectomy radiation: incidence and risk factors. Ann Surg Oncol 2004;11:573-80.

4. Zuther JE. Lymphedema management: the comprehensive guide for practitioners. 1st ed. New York: Thieme; 2005.

5. Weissleder H, Schuchhardt C. Lymphedema diagnosis and therapy. 4th ed. Baden-Baden: Viavital Verlag Gmbh; 2008.

6. Schuchhardt C, Foldi E, Foldi M. Diagnostic-therapylong term observation of lymphedema following cancer treatment. J Exper Clin Hematol 1985;51:175.

7. Lee BB, Bergan JJ. New clinical and laboratory staging systems to improve management of chronic lymphedema. Lymphology 2005;38:122-9.

8. Taylor R, Jayasinghe UW, Koelmeyer L, Ung O, Boyages J. Reliability and validity of arm volume measurements for assessment of lymphedema. Phys Ther 2006;86:205-14.

9. Ahmed RL, Prizment A, Lazovich D, Schmitz KH, Folsom AR. Lymphedema and quality of life in breast cancer survivors: the Iowa Women's Health Study. J Clin Oncol 2008;26:5689-96.

10. Beaton R, Pagdin-Friesen W, Robertson C, Vigar C, Watson H, Harris SR. Effects of exercise intervention on persons with metastatic cancer: a systematic review. Physiother Can 2009;61:141-53.

11. Spiegel D, Bloom JR, Kraemer HC, Gottheil E. Effect of psychosocial treatment on survival of patients with metastatic breast cancer. Lancet 1989;2:888-91.

12. Spiegel D, Bloom JR, Yalom I. Group support for patients with metastatic cancer. A randomized outcome study. Arch Gen Psychiatry 1981;38:527-33.

13. Spiegel D. Psychosocial aspects of breast cancer treatment. Semin Oncol 1997;24(1 Suppl 1):S1-36-S1-47. 
14. Herpertz U. Malignant lymphedema. Z Lymphol 1990;14:17-23.

15. Piller N, Carati C. The diagnosis and treatment of peripheral lymphedema. Lymphology 2009;42:146-7.

16. Preisler VK, Hagen R, Hoppe F. Indications and risks of manual lymph drainage in head-neck tumors. Laryngorhinootologie 1998;77:207-12.
17. Godette K, Mondry TE, Johnstone PA. Can manual treatment of lymphedema promote metastasis? J Soc Integr Oncol 2006;4:8-12.

18. Pinell XA, Kirkpatrick SH, Hawkins K, Mondry TE, Johnstone PA. Manipulative therapy of secondary lymphedema in the presence of locoregional tumors. Cancer 2008;112:950-4. 